Document downloaded from:

http://hdl.handle.net/10251/176484

This paper must be cited as:

Doménech-Carbó, A.; Dias, D.; Domenech Carbo, MT. (2020). Cation and anion electrochemically assisted solid-state transformations of malachite green. Physical Chemistry Chemical Physics. 22(3):1502-1510. https://doi.org/10.1039/c9cp05835d

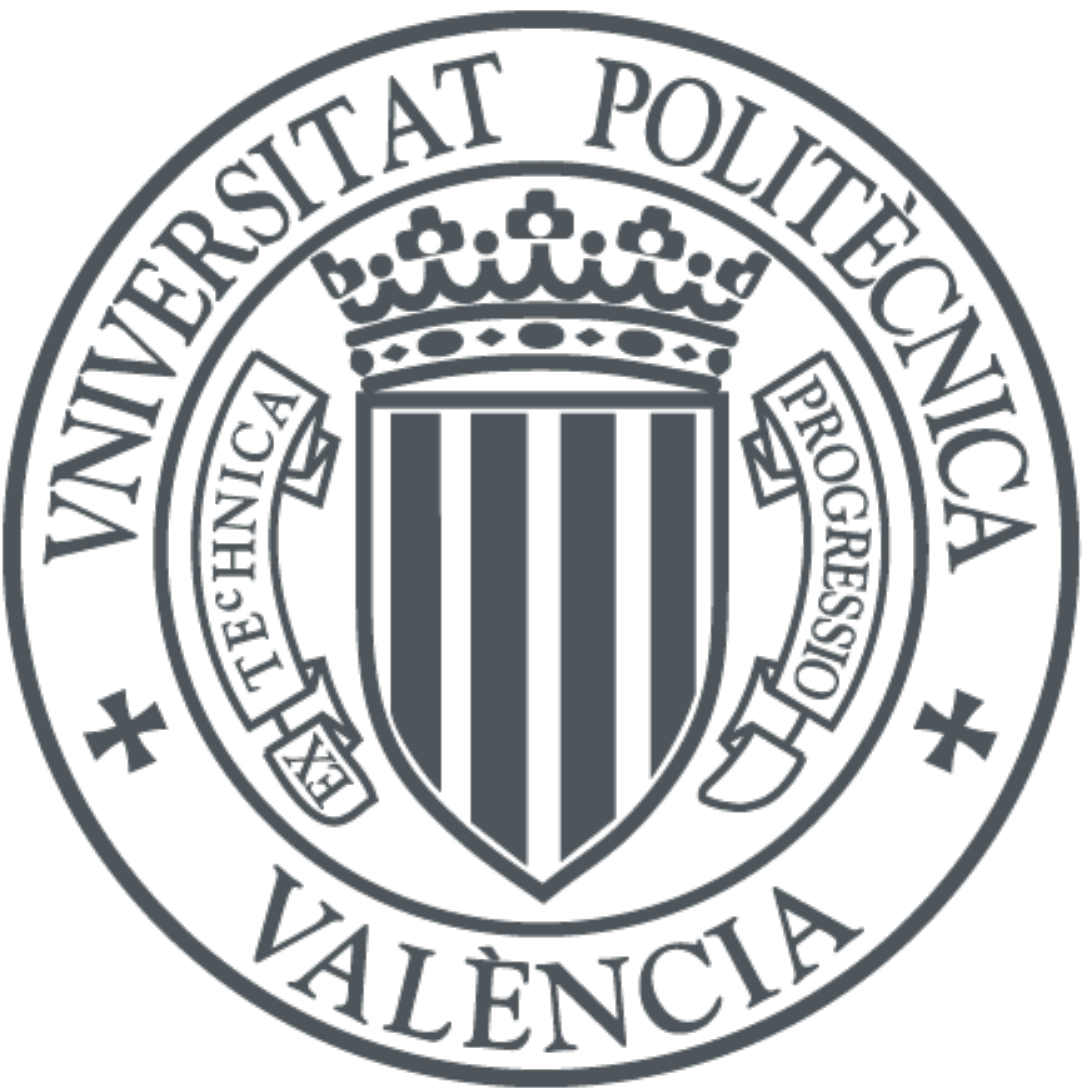

The final publication is available at

https://doi.org/10.1039/c9cp05835d

Copyright The Royal Society of Chemistry

Additional Information 


\title{
Cation and anion electrochemically assisted solid-state transformations of malachite green
}

\author{
Antonio Doménech-Carbó*a ${ }^{\mathrm{a}}$, Daiane Dias ${ }^{\mathrm{b}}$, María Teresa Doménech-Carbóc
}

a Departament de Química analítica, Universitat de València, Dr. Moliner, 50, 46100 Burjassot (València) Spain.

b Laboratório de Eletro-Espectro Analítica (LEEA), Escola de Química e Alimentos, Universidade Federal do Rio Grande, Av. Itália, km 8, Rio Grande, 96203-900, RS, Brazil.

${ }^{c}$ Institut de Restauració del Patrimoni, Universitat Politècnica de València, Camí de Vera 14, 46022, València, Spain.

* Corresponding author, e-mail: e-mail: antonio.domenech@uv.es.

\begin{abstract}
The possibility of the electrochemical promotion of different solid-to-solid transformations including the performance of successive cation and anion insertion processes has been tested using malachite green, a triphenylmethane dye, in contact with aqueous $\mathrm{NaCl}$ electrolyte. Electrochemical data using the voltammetry of microparticles methodology reveal significant differences with the solution phase electrochemistry of the dye. Voltammetric data, combined with atomic force microscopy, focusing ion beam-field emission scanning electron microscope, and highresolution field emission scanning electron microscopy permits characterizing the oxidative dissolution, oxidation with anion insertion, reduction with cation insertion and reduction with anion issue processes whose thermochemical aspects, involving separate ion and electron transport contributions, are discussed.
\end{abstract}

Keywords: Electrochemistry; Malachite Green; Solid State; Ion insertion; Atomic Force Microscopy. 


\section{Introduction}

Electropreparative procedures have received attention for their capability to produce 'clean' and highly selective syntheses with high yields. ${ }^{1}$ Although, in general, the reagents and products are in solution, there are examples of electrosynthesis yielding polymeric films ${ }^{2-4}$ and solids. ${ }^{5-7}$ The scope of solid electrosynthesis was enhanced by the development of the voltammetry of immobilized particles (VIMP), a solid-state technique, by Scholz et al. ${ }^{8-10}$ based on the abrasive attachment of solid nonconducting particles to an inert electrode, typically graphite, in contact with a suitable electrolyte. Successive reviews ${ }^{11-14}$ have described the stages in expanding of this technique, with particular emphasis on its analytical capabilities. ${ }^{15}$

Using the VIMP methodology, Inzelt $^{16}$ studied the oxidative dimerizations and polymerizations of solid diphenylamine attached to platinum and gold electrodes while Bond et al. studied solid-to-solid transformations in 7,7,8,8-tetracyanoquinodimethane (TCNQ) under different conditions. ${ }^{17}$ More recently, Marken et al. expanded these methodologies using electrocatalytic strategies incorporating redox mediators in the solution phase, ${ }^{18-21}$ and revised the perspectives of three-phase junctions in electrochemistry and photoelectrochemistry. ${ }^{22}$

The most significant fraction of VIMP processes dealing with electrosynthesis is those consisting of the solid-to-solid transformations where an ion-permeable solid attached to an inert electrode is electrochemically reduced or oxidized to a second solid. For reasons of charge conservation, these processes involve the coupled transfer of chargebalancing cations or anions from/to the electrolyte and electrons from/to the base electrode. A typical example is Prussian blue and other hexacyanometallates, where different cations can occupy interstitial positions within the solid phase. ${ }^{23-25}$ In the electrochemistry of organic solids in contact with aqueous electrolytes, protons act as a charge-balancing species so that reduction/oxidation processes can produce significant modifications in the covalent bonding and/or intermolecular hydrogen bonding. ${ }^{26,27}$

Recently, Scholz et al. ${ }^{28}$ studied the difference between the voltammetric and potentiometric responses of a tungsten bronze electrode, concluding that while in voltammetry, ion insertion/release phenomena under potentiometric ion transfer 
conditions parallels that occurring in glass electrodes..$^{29,30}$ As a result, a separation between the electronic and ionic contributions to the Gibbs energy can be achieved, ${ }^{28,31,32}$ prompting the experimental determination of thermochemical properties for single-ion solvation using membrane-modified liquid-liquid interfaces, ${ }^{33}$ micro/nanoholes, ${ }^{34}$ and triple-phase boundary measurements at microdroplets immobilized on electrode surfaces, ${ }^{35}$ among other procedures.

There are, however, relatively few studies in which the structural changes occurring in these processes are studied at the nanoscopic scale, and the production mode of the solid product appears to be determined by different factors so that the new solid can segregate forming inclusions in the parent solid phase, ${ }^{36}$ yield bilayered structures ${ }^{37,38}$ or form new solids, clearly differing in the morphology and crystal size. ${ }^{39,40}$

The purpose of the current work is to study both the thermochemical and structural aspects involved in the solid state electrochemistry of malachite green (MG). This is a member of the triphenylmethane dyes and is widely used as a dye in photoelectrochemical applications ${ }^{41-43}$ whose low solubility in water suggests the possibility of a flexible promotion of different solid-to-solid transformations and, in particular, testing the possibility of successive cation and anion insertion processes within the same series of electrochemical turnovers. Accordingly, voltammetry and open circuit potential measurements, coupled with controlled potential electrolysis of MG in contact with aqueous $\mathrm{NaCl}$ solutions, were monitored by atomic force microscopy (AFM) coupled to VIMP, focusing ion beam-field emission scanning electron microscope (FIB-FESEM), high-resolution field emission scanning electron microscopy (HRFESM-EDX), and attenuated total reflectance-Fourier transform infrared spectroscopy (ATR-FTIR).

\section{Experimental}

MG (Fluka) was used. Voltammetric and open circuit potential experiments were performed at $298 \pm 1 \mathrm{~K}$ in a three-electrode cell using a $\mathrm{CH} 720 \mathrm{c}$ potentiostat (Cambria Scientific, Llwynhendy, Llanelli UK) with an MG-modified graphite working electrode, a platinum wire auxiliary electrode and an $\mathrm{Ag} / \mathrm{AgCl}(3 \mathrm{M} \mathrm{NaCl})$ reference electrode in 
contact with $\mathrm{NaCl}$ aqueous solutions in concentrations between 0.01 and $1.0 \mathrm{M}$. Electrode modification was carried out by lightly pressing $2 \mathrm{~mm}$ diameter graphite bars (Faber-Castell, HS pencil leads) over a thin layer of MG powdered on the plane surface of an agate mortar. After applying of different potential inputs, the working electrode was separated from the electrolyte, rinsed repeatedly but smoothly with water and dried in air. Then, the remaining dye particles were mechanically separated with the help of a scalpel.

The energy dispersive X-ray microanalysis was performed in trenches with a high resolution field emission scanning electron microscope (HRFESM-EDX) Zeiss (Orsay Physics Kleindiek Oxford Instruments) model GeminiSEM 500 with an OxfordInstrument X-ray microanalysis, which was controlled using the Aztec software. A voltage of $5 \mathrm{kV}$ and a working distance of 6-7 $\mathrm{mm}$ were applied. The ZAF method was followed to correct the inter-elemental effects in the semiquantitative microanalysis. A 100 s counting time was used. Secondary electron images and X-ray spectra were obtained in cross-sections. The latter were acquired in the spot mode.

The surface analysis runs to characterize the micromorphology and variations in the elemental composition on the surface and sub-surface of the MG particles were carried out by performing trenches using a field emission scanning electron microscope coupled to a focused ion beam Zeiss (Orsay Physics Kleindiek Oxford Instruments), model Auriga compact equipment. The operating conditions were $30 \mathrm{kV}$ voltage and current intensities $500 \mu \mathrm{A}$ and $20 \mathrm{nA}$ in the FIB to generate the focused beam of Ga ions. The $\mathrm{Ga}$ beam impacts perpendicularly on the plane of the vertical wall of the trench by tilting the stage $54^{\circ}$ from where the MG grain was placed. A voltage of $2 \mathrm{kV}$ was used in FESEM to acquire electron images. For protecting the surface of the gold object during application of the Ga beam, the area where the trench was performed was first coated with $300 \mathrm{~nm}$ Pt layer in an $8 \times 10 \mu \mathrm{m}$ area.

In situ AFM-monitored electrochemical experiments were performed using a multimode AFM (Digital Instruments VEECO Methodology Group, USA) with a NanoScope IIIa controller and a J-type scanner (max. scan size of $150 \times 150 \times 6 \mu \mathrm{m}$ ). MG particles were transferred to a carbon plate by pressing the plate $(1 \times 1 \times 0.2 \mathrm{~cm})$ over a thin layer of $\mathrm{MG}$ 
particles (ca. $100 \mathrm{mg}$ ) extended over an agate mortar (see also ${ }^{44}$ ). The topography of the samples was studied in contact mode. An Olympus oxide-sharpened silicon nitride probe (VEECO Methodology Group, model NP-S) was used with a V-shaped cantilever configuration. The spring constant is $0.06 \mathrm{~N} / \mathrm{m}$ and the tip radius of curvature is $5-40 \mathrm{~nm}$.

ATR-FTIR spectra of samples and reference materials were obtained using a Vertex 70 Fourier transform infrared spectrometer with an FR-DTGS (fast recovery deuterated triglycine sulphate) temperature-stabilized coated detector. The number of co-added scans was 32. The resolution was $4 \mathrm{~cm}^{-1}$. In coupled VIMP and ATR-FTIR experiments, different constant potential inputs were applied to $\mathrm{MG}$ deposits on a $5 \mathrm{~mm}$ diameter graphite electrode in contact with $0.10 \mathrm{M} \mathrm{NaCl}$ for $10 \mathrm{~min}$. After this, the electrode was repeatedly rinsed with water and dried in air. Then, a set of microcrystals were separated with a microscalpel and transferred to the ATR window.

\section{Results and discussion}

\section{Voltammetric pattern}

Figure 1 compares the $\mathrm{CV}$ responses of a ca. $0.30 \mathrm{mM}$ solution of malachite green in 1.0 $\mathrm{M} \mathrm{NaCl}$ aqueous solution and a microparticulate deposit of the dye on a graphite bar in contact with $1.0 \mathrm{M} \mathrm{NaCl}$. In positive-going potential voltammograms, the $\mathrm{MG}$ solution (Figure 1a) displays successive anodic signals at $0.56\left(\mathrm{~A}_{1}\right)$ and $0.79 \mathrm{~V}\left(\mathrm{~A}_{2}\right)$. In the subsequent cathodic scan, only one reduction peak at $0.16 \mathrm{~V}\left(\mathrm{C}_{3}\right)$ was recorded, preceded by weak shoulders at ca. $0.70\left(\mathrm{C}_{2}\right)$ and $0.50 \mathrm{~V}\left(\mathrm{C}_{1}\right)$. These signals were followed in the second anodic scan by an oxidation peak at $0.28 \mathrm{~V}\left(\mathrm{~A}_{3}\right)$, defining an essentially reversible couple $\mathrm{C}_{3} / \mathrm{A}_{3}$ at a $0.22 \mathrm{~V}$ equilibrium potential.

The voltammogram of the solid deposit in contact with $1.0 \mathrm{M} \mathrm{NaCl}$ solution is depicted in Figure 1b. Here, oxidation peaks at $0.65\left(\mathrm{~A}_{1}\right)$ and $0.88 \mathrm{~V}\left(\mathrm{~A}_{2}\right)$ appear in the initial anodic scan voltammogram accompanied, in the subsequent cathodic scan, by a main cathodic signal at $0.28 \mathrm{~V}\left(\mathrm{C}_{4}\right)$ coupled with a main oxidation signal at $0.35 \mathrm{~V}\left(\mathrm{~A}_{4}\right)$, thus defining a voltammetric pattern differing from that recorded for MG in solution. Three replicate measurements were performed for solid-state voltammetry using renewed microparticulate deposits of MG in each. Since the amount of solid cannot be accurately controlled, the variation in peak currents ranges between $10 \%$ and $20 \%$ while the dispersion of peak potentials reached values between 5 and $30 \mathrm{mV}$. 
The differences between the voltammetric responses in solution and solid-state increased in repetitive voltammetry on restricting the potential range between 0.60 and $-0.20 \mathrm{~V}$ vs. $\mathrm{Ag} / \mathrm{AgCl}$ where, as shown in Figure 2a, only one reversible couple $\mathrm{C}_{3} / \mathrm{A}_{3}$ was recorded in solution in contrast with the three couples at equilibrium potentials of $0.35\left(\mathrm{C}_{4} / \mathrm{A}_{4}\right), 0.22\left(\mathrm{C}_{3} / \mathrm{A}_{3}\right)$, and $0.07 \mathrm{~V}\left(\mathrm{C}_{5} / \mathrm{A}_{5}\right)$ at with MG-modified electrodes (Figure $2 b)$. This voltammetry differed in the position and relative height of the peaks on varying the concentration of $\mathrm{NaCl}$, a feature characterizing the solid-state electrochemistry of ion-insertion solids. ${ }^{11-15}$

The solution-phase electrochemistry of $\mathrm{MG}$ can be interpreted, following the literature, ${ }^{45-47}$ in terms of multistep oxidation resulting in the formation of a hydroxylated form through Process $A_{1}$. This species is reversibly reduced to the hydroxylated leuco form via the $\mathrm{C}_{3} / \mathrm{A}_{3}$ couple but can also be irreversibly oxidized via the Process $\mathrm{A}_{2}$ to a dihydroxylated species, as shown in Figure 3.

The significant differences between the solution-phase and solid-state voltammetry of MG suggest that genuine solid-state processes occur (although accompanied, to some extent, by solution-phase processes due to the small fraction of MG that is dissolved in the time scale of the voltammetric experiment). To interpret voltammetric data, it is pertinent to note that in solids permeable to both cations and anions, the reduction processes can consist of the ingress of electrons coupled to the entrance of electrolyte cations or the issue of anions from the solid to the electrolyte. Similarly, the oxidation processes can involve the release of electrons and the issue of cations or the ingress of anions to/from the electrolyte. The crucial point for the purposes of this work is to elucidate the effective occurrence of potential-driven ion insertion processes. This requires the use of nanoscopic techniques coupled with electrochemical measurements.

\section{Nanoscopic features}

To test the occurrence of these processes in MG electrochemistry, a series of experiments was performed, applying a sequence of constant potential steps to microparticulate MG deposits on graphite electrodes and recovering the solid particles remaining at the electrode. The optical microscopy images of an MG deposit on a graphite electrode in contact with $0.10 \mathrm{M} \mathrm{NaCl}$ obtained during the application of a 
sequence of potentials mimicking the voltammograms in Figure 1 is provided as Supplementary Information, Figure S.1. The initial deposit looks like irregular light blue crystals. After application of a $0.50 \mathrm{~V}$ potential for $5 \mathrm{~min}$, the deposit appears as aggregates of smaller and irregular greenish crystals. The colour change suggests that the parent MG experienced solid-to-solid transformation as a result of the redox process while the apparent decrease in crystal size would be consistent with the appearance of some oxidative dissolution, as discussed in detail below (vide infra). The subsequent application of a $-0.25 \mathrm{~V}$ potential step for 5 min changes the morphology and colour of the grains, now appearing as dark grey irregular crystals without an apparent size change. This situation can be ascribed to a 'pure' solid-to-solid transformation. Finally, further application of a $0.25 \mathrm{~V}$ potential for $5 \mathrm{~min}$ yields several black irregularly rounded features superimposed to dark grey irregular aggregates of crystals, thus suggesting the formation of segregated structures growing in the vicinity of the original grains. These features suggest troubled crystalline transformation that can be interpreted (vide infra) as a result of multilayer solid-to-solid generation.

AFM monitoring the application of the same sequence of potential inputs to a microparticulate deposit of MG on a graphite plate revealed parallel morphological changes. Figure 4 depicts the topographic images of a grain of malachite green in contact with $0.10 \mathrm{M} \mathrm{NaCl}$ before (a) and after application of successive potential inputs of b) 0.50, c) -0.25 , d) $0.25 \mathrm{~V}$ vs. $\mathrm{Ag} / \mathrm{AgCl}$ for $5 \mathrm{~min}$ each. In the initial oxidative step, the size of the MG crystal becomes laterally narrowed (marked by the dotted arrow in Fig. 4b) while the region in contact with the graphite is enlarged (continuous arrow in Fig. 4b). These features suggest that the initial MG oxidation can follow a dual pathway involving an oxidative dissolution simultaneous to solid-state, ion-assisted oxidation (vide infra).

In contrast, the subsequent application of a cathodic input at $-0.25 \mathrm{~V}$ yields an engrossment of the crystal. A new crystalline phase appears (marked by an arrow in Fig. 4c), suggesting that a solid-to-solid transformation with segregation of a new phase takes place. This last phase disappears when an anodic input of $0.25 \mathrm{~V}$ is subsequently applied. The gross base region maintains its volume (Fig. 4d), thus suggesting that the previous process can be reversed. 
Monitoring the sequence of oxidative and reductive potential inputs using FESEM/EDX confirms the entrance of electrolyte charge-balancing ions during electrochemical runs. The most relevant data correspond to the transition from the first oxidized form, obtained by application of an oxidative step at $0.80 \mathrm{~V}$, to its reduced form, obtained by applying a subsequent reductive step at $-0.25 \mathrm{~V}$. As shown in Fig. 5, where a,b) show EDX spectra and c,d) show FESEM images of the corresponding grains. The EDX spectrum recorded after the first oxidative step shows a clearly marked $\mathrm{Cl}$ peak, thus denoting that chloride ions have entered in the MG crystal. After the subsequent cathodic step, the EDX spectrum shows the presence of $\mathrm{Na}$, in agreement with the expected insertion of $\mathrm{Na}^{+}$ions into the solid accompanying the solid-state reduction process.

This is in agreement with the theoretical expectations derived from the model of Lovric, Scholz, Oldham and co-workers on the electrochemistry of ion-insertion solids. ${ }^{48-53}$ Here, the electrochemical reduction (oxidation) of a solid able to be permeated by electrolyte ions has to be accompanied, for reasons of charge conservation, by the ingress of cations (anions) from the electrolyte or, alternatively, by the issue of mobile anions (cations) from the parent compound. Accordingly, EDX data in Fig. 5 denote that Process $\mathrm{A}_{1}$ maintains or increases the $\mathrm{Cl}$ content of the parent $\mathrm{MG}$ solid and that Process $\mathrm{C}_{4}$ involves the ingress of $\mathrm{Na}^{+}$cations from the electrolyte.

In turn, FIB-FESEM experiments to obtain the secondary electron images on MG grains during different steps along the aforementioned sequence of potential steps after performing a $10 \times 10 \mu \mathrm{m}$ trench with a square cross-section and 10-15 $\mu \mathrm{m}$ depth, also provided relevant information on the solid-state transformation during electrochemical turnovers. Fig. 6a shows the FESEM images of an MG crystal after applying of the initial oxidative step at $0.80 \mathrm{~V}$. Here, one can see the appearance of ca. $100 \mathrm{~nm}$ long crystal bars deposited over the rough surface of the crystal. The image of the trench in Fig. $6 \mathrm{~b}$ shows a uniform cross-section. In contrast, after application of a cathodic potential step at $-0.25 \mathrm{~V}$ (Fig. 6c), the cross-section of the trench shows an upper layer clearly differing from the uniform deeper region, thus suggesting that there is phase segregation accompanying the reductive process. Remarkably, the subsequent 
application of an oxidative step at $0.25 \mathrm{~V}$ results in a comparable two-phase featured trench section now accompanied by voids in the inner layer, as can be seen in Fig. 6d.

The aforementioned sequence of solid-state electrochemical processes was also monitored by ATR-FTIR, as described in the Experimental section. Representative infrared spectra are depicted in Figure S.2 of Supplementary Information, corresponding to a deposit of MG crystals a) before and after application of successive potential inputs for $10 \mathrm{~min}$ at b) $1.0 \mathrm{~V}$ and c) $-0.5 \mathrm{~V}$ in contact with $0.10 \mathrm{M} \mathrm{NaCl}$ aqueous solution. The relevant features to underline are: i) the $\mathrm{N}=\mathrm{H}$ band at ca. $1700 \mathrm{~cm}^{-1}$ disappears after the initial oxidative step and ii) only very weak $\mathrm{O}-\mathrm{H}$ bands at ca. $3400 \mathrm{~cm}^{-1}$ are recorded and remain essentially unchanged after electrochemical runs. These features suggest that the redox processes in solid-state do not follow the same pathway as those in solution; in particular, it appears that there is no formation of hydroxylated leuco forms.

\section{Electrochemical pathways}

To rationalize these features, there is need to consider the possibility of at least two types of electrochemical processes affecting microcrystalline deposits: i) reductive or oxidative dissolutions in which a soluble product is formed and ii) solid-to-solid transformations, often involving the segregation of different crystalline phases.

First, the initial oxidation of microparticulate MG deposits can be described in terms of the competing superposition of two pathways. The first involves oxidative dissolution with the formation of a hydroxylated oxidized form in solution with the subsequent repetition of the solution-phase electrochemistry shown in Figure 3.

The second consists of solid-to-solid transformations due to the ingress/issue of electrolyte counterions from/to the electrolyte coupled to electron transfer processes through the particle-base electrode interface, following the general scheme theoretically described by Lovric, Scholz, Oldham and co-workers. ${ }^{48-53}$ Since, according to ATRFTIR data, there is no formation of hydroxylated species, one can hypothesize that solid-state redox transformations are initiated by a one-electron oxidation involving the ingress of chloride ions, consistent with the SEM/EDX data in Figure 5. The subsequent application of a cathodic input determines the appearance of Process $\mathrm{C}_{4}$ that, as judged 
by FESEM/EDX data in Figure 5, consists of the coupled entrance of $\mathrm{Na}^{+}$ions from the electrolyte and electrons from the base electrode to form a solid, segregated as a new solid phase, as seen in the AFM data in Figure 4 and FIB-FESEM data in Figure 6. This process would compete with the solid-state reduction involving the release of chloride ions from the solid, which can be assigned to the cathodic signal $\mathrm{C}_{5}$. These pathways are shown in Figure 7.

Detailed examination of electrochemical data, however, suggested the existence of a more complicated scenario. First, experiments on repetitive voltammetry resulted in a clear difference between the signals corresponding to the oxidation of solid MG and the couple $\mathrm{C}_{3} / \mathrm{A}_{3}$. Figure $8 \mathrm{a}$ compares the variation of the peak current $\left(i_{\mathrm{p}}\right)$ with the scan number for the signals $A_{2}$ and $C_{3}$. This variation is monotonically decreasing for $A_{2}$ but looks like at least two differently decreasing regions for $\mathrm{C}_{3}$. This last situation parallels that described by Kaluza et al. $^{21}$ on studying the solid-solid EC' TEMPO electrocatalytic conversion of diphenylcarbinol to benzophenone where two successive kinetic features appeared. Consistently, the peak potential for signal $\mathrm{C}_{3}$ shifts negatively in successive scans but does not show a uniform variation.

\section{Thermochemical aspects}

According to the reaction scheme depicted in Figure 7 , the couples $\mathrm{C}_{4} / \mathrm{A}_{4}$ and $\mathrm{C}_{5} / \mathrm{A}_{5}$ correspond, respectively, to the reversible electrochemical processes:

$$
\begin{gathered}
\left\{\mathrm{MG}^{2+} 2\left(\mathrm{Cl}^{-}\right)\right\}_{\text {solid }}+\mathrm{Na}^{+}{ }_{\mathrm{aq}}+\mathrm{e}^{-} \rightarrow\left\{\mathrm{MG}^{+}\left(\mathrm{Na}^{+}\right) 2\left(\mathrm{Cl}^{-}\right)\right\}_{\text {solid }} \\
\left\{\mathrm{MG}^{2+} 2\left(\mathrm{Cl}^{-}\right)\right\}_{\text {solid }}+\mathrm{e}^{-} \rightarrow\left\{\mathrm{MG}^{+}\left(\mathrm{Cl}^{-}\right)\right\}_{\text {solid }}+\mathrm{Cl}^{-} \text {aq }
\end{gathered}
$$

Under conditions of electrochemical reversibility, the respective midpeak potentials, $E_{\mathrm{mp}}\left(\mathrm{C}_{4} / \mathrm{A}_{4}\right)$ and $E_{\mathrm{mp}}\left(\mathrm{C}_{5} / \mathrm{A}_{5}\right)$ can be expressed as:

$$
\begin{gathered}
E_{\mathrm{mp}}\left(\mathrm{C}_{4} / \mathrm{A}_{4}\right)=E_{4 \mathrm{E}}^{\mathrm{o}}+\frac{R T}{F} \ln \frac{a_{\left\{\mathrm{MG}^{2+} 2\left(\mathrm{Cl}^{-}\right)\right\}} a_{\mathrm{Na}^{+}}}{a_{\left\{\mathrm{MG}^{+}\left(\mathrm{Na}^{+}\right) 2\left(\mathrm{Cl}^{-}\right)\right\}}} \\
E_{\mathrm{mp}}\left(\mathrm{C}_{5} / \mathrm{A}_{5}\right)=E^{\mathrm{o}}{ }_{5 \mathrm{E}}+\frac{R T}{F} \ln \frac{a_{\left\{\mathrm{MG}^{2+} 2\left(\mathrm{Cl}^{-}\right)\right\}}}{a_{\left\{\mathrm{MG}^{+}\left(\mathrm{Cl}^{-}\right)\right\}} a_{\mathrm{Cl}^{-}}}
\end{gathered}
$$


In these equations, $E_{4 \mathrm{E}}^{\mathrm{o}}$ and $E_{5 \mathrm{E}}^{\mathrm{o}}$ represent the formal electrode potentials of the respective couples and $a_{\mathrm{J}}$ the thermodynamic activity of the J-species. In these processes, a layer of the corresponding reduced form is formed in the crystals of the parent MG form so that, under conditions of open circuit potential (OCP) measurements, interfacial equilibria:

$$
\begin{aligned}
& \left\{\mathrm{MG}^{+} 2\left(\mathrm{Cl}^{-}\right)\right\}_{\text {solid }}+\mathrm{Na}^{+}{ }_{\mathrm{aq}} \rightarrow\left\{\mathrm{MG}^{+}\left(\mathrm{Na}^{+}\right) 2\left(\mathrm{Cl}^{-}\right)\right\}_{\text {solid }} \\
& \left\{\mathrm{MG}^{+} 2\left(\mathrm{Cl}^{-}\right)\right\}_{\text {solid }} \rightarrow\left\{\mathrm{MG}^{+}\left(\mathrm{Cl}^{-}\right)\right\}_{\text {solid }}+\mathrm{Cl}^{-} \text {aq }
\end{aligned}
$$

should occur. These equilibria can formally be represented as the combination of the processes described by Eqs. (1) and (2) and the electron transfer process:

$$
\left\{\mathrm{MG}^{2+} 2\left(\mathrm{Cl}^{-}\right)\right\}_{\text {solid }}+\mathrm{e}^{-} \rightarrow\left\{\mathrm{MG}^{+} 2\left(\mathrm{Cl}^{-}\right)\right\}_{\text {solid }}
$$

whose corresponding Nernst equations are:

$$
E_{\mathrm{I}}=E_{\mathrm{I}}^{\mathrm{o}}+\frac{R T}{F} \ln \frac{a_{\left\{\mathrm{MG}^{+} 2\left(\mathrm{Cl}^{-}\right)\right\}}}{a_{\left\{\mathrm{MG}^{+}\left(\mathrm{Cl}^{-}\right)\right\}}}
$$

with $E_{I}^{\mathrm{o}}$ being the formal electrode potentials of the couple. Combining the above equations, the OCP potentials will be:

$$
\begin{gathered}
E_{\mathrm{OCP}}\left(\mathrm{C}_{4} / \mathrm{A}_{4}\right)=E^{\mathbf{o}}{ }_{4 \mathrm{E}}-E^{\mathbf{o}}{ }_{\mathrm{I}}+\frac{R T}{F} \ln \frac{a_{\left\{\mathrm{MG}^{2+} 2\left(\mathrm{Cl}^{-}\right)\right\}} a_{\mathrm{Na}^{+}}}{a_{\left\{\mathrm{MG}^{+}\left(\mathrm{Na}^{+}\right) 2\left(\mathrm{Cl}^{-}\right)\right\}}} \\
E_{\mathrm{OCP}}\left(\mathrm{C}_{5} / \mathrm{A}_{5}\right)=E^{\mathbf{o}}{ }_{5 \mathrm{E}}-E^{\mathbf{o}}{ }_{\mathrm{I}}+\frac{R T}{F} \ln \frac{a_{\left\{\mathrm{MG}^{2+} 2\left(\mathrm{Cl}^{-}\right)\right\}}}{a_{\left\{\mathrm{MG}^{+}\left(\mathrm{Cl}^{-}\right)\right\}} a_{\mathrm{Cl}^{-}}}
\end{gathered}
$$

In solutions containing a large concentration of $\mathrm{Na}^{+}$or $\mathrm{Cl}^{-}$, the activities of the MGbased species in Eqs. (9) and (10) can be taken as essentially constant and equal to one so that the differences between the $E_{\mathrm{mp}}$ and $E_{\mathrm{OCP}}$ potentials become independent of the electrolyte ion: ${ }^{28,31,32}$ 


$$
\begin{aligned}
& E_{\mathrm{mp}}\left(\mathrm{C}_{4} / \mathrm{A}_{4}\right)-E_{\mathrm{OCP}}\left(\mathrm{C}_{4} / \mathrm{A}_{4}\right)=E^{\mathbf{o}}{ }_{4 \mathrm{E}}-E^{\mathbf{o}}{ }_{\mathrm{I}} \\
& E_{\mathrm{mp}}\left(\mathrm{C}_{5} / \mathrm{A}_{5}\right)-E_{\mathrm{OCP}}\left(\mathrm{C}_{5} / \mathrm{A}_{5}\right)=E^{\mathbf{o}}{ }_{5 \mathrm{E}}-E^{\mathbf{o}}{ }_{\mathrm{I}}
\end{aligned}
$$

Notice that the measured OCP's also contain the potential of the reference electrode, the potential drops at the base electrode $/\left\{\mathrm{MG}^{2+} 2\left(\mathrm{Cl}^{-}\right)\right\}_{\text {solid }}$ and either the $\left\{\mathrm{MG}^{2+} 2\left(\mathrm{Cl}^{-}\right)\right\}_{\text {solid }} /\left\{\mathrm{MG}^{+}\left(\mathrm{Na}^{+}\right) 2\left(\mathrm{Cl}^{-}\right)\right\}_{\text {solid }}$ and $\left\{\mathrm{MG}^{2+} 2\left(\mathrm{Cl}^{-}\right)\right\}_{\text {solid }} /\left\{\mathrm{MG}^{+}\left(\mathrm{Cl}^{-}\right)\right\}_{\text {solid }}$ inter faces. All these potentials will remain constant during all measurements and, hence, can be omitted here.

Experimental data for the variation of the open circuit potential $\left(E_{\mathrm{OCP}}\right)$ with time are depicted in Figure 8. After application of a constant $1.0 \mathrm{~V}$ potential input for $5 \mathrm{~min}$, the OCP reaches an initial value of ca. $0.7 \mathrm{~V}$ which decreases with time and tends toward a limiting value of $0.40 \mathrm{~V}$. The successive application of potential inputs at 1.0 and 0.35 $\mathrm{V}$ for $5 \mathrm{~min}$ each, results in an initial OCP of ca. $0.36 \mathrm{~V}$ tending to a limiting potential of $0.24 \mathrm{~V}$. If $\mathrm{a}-0.25 \mathrm{~V}$ potential step is applied, the OCP varies from ca. $-0.10 \mathrm{~V}$ to a limiting value of $-0.01 \mathrm{~V}$. Accordingly, both $E_{\mathrm{mp}}\left(\mathrm{C}_{4} / \mathrm{A}_{4}\right)-E_{\mathrm{OCP}}\left(\mathrm{C}_{4} / \mathrm{A}_{4}\right)$ and $E_{\mathrm{mp}}\left(\mathrm{C}_{5} / \mathrm{A}_{5}\right)$ - $E_{\mathrm{OCP}}\left(\mathrm{C}_{5} / \mathrm{A}_{5}\right)$ are equal to $80 \mathrm{mV}$, confirming the theoretically predicted difference between mid-peak voltammetric potentials and open circuit potentials in ion insertion/release electrochemical processes. The corresponding curves showing the rate OCP variation with time, $\Delta E_{\mathrm{OCP}} / \Delta t$, are shown in Figure $8 \mathrm{~b}$, clearly showing the common tendency to zero at times near 5 min.

\section{The ion-insertion scenario}

The solid-state electrochemistry of $\mathrm{MG}$ in contact with aqueous $\mathrm{NaCl}$ can be viewed within the context of redox-driven solid state transformations. Cation insertion to form M-TCNQs has been extensively studied by Bond et al., ${ }^{39,40,54-56}$ while examples of anion insertion on heteropolymetallic clusters bearing ferrocenyl groups ${ }^{57-59}$ and bisferrocenylfunctionalized pseudopeptides ${ }^{32}$ have been reported. Finally, proton insertion/deinsertion is involved in the solid-state electrochemistry of several organic compounds such as azobenzene, ${ }^{5} 2$-mercaptobenzoxazole,${ }^{6}$ and dyes, ${ }^{26}$ among others. ${ }^{27}$

The data reported here clearly suggests that the electrochemistry of MG in chloride media presents, a peculiar case of oxidative dissolution and cation- and anion-assisted 
processes. In particular, reduction with cation insertion is accompanied by the competing reduction with anion issue. From a mechanistic view, the studied system appears to differ from the electrochemical generation of M-TCNQs, where a first step of nucleation at the triple-phase particle/base electrode/electrolyte is followed by fast growth kinetics, ${ }^{60,61}$ or the oxidation of 2 -mercaptobenzoxazole where adsorption to form supra-monolayer coverage appears to be involved. ${ }^{6}$

The initial oxidation of MG crystalline deposits via the partial oxidative dissolution and solid-to-solid transformation with chloride insertion is shown in Figure 9a. The coexistence of both processes is consistent with AFM and SEM images in Figures 4 and 5. The subsequent application of cathodic inputs to the remaining solid determines the forms of a layer of reduced solid via $\mathrm{Na}^{+}$ion insertion which segregates from the original crystal, as shown in Figure 9b. Interestingly, SEM images do not show the pore formation $^{58-59}$ or intercalation features ${ }^{18-21}$ observed in other systems. Repetitively cycling the potential scan, as shown in Figure $2 b$, slowly modified the voltammetric profile, thus suggesting the formation of successive differently $\mathrm{Na}^{+}-$and $\mathrm{Cl}^{-}$-enriched layers in the MG crystals, as illustrated in Figure 9. Conjointly considered, the reported solid-state electrochemistry of MG provides a versatile scenario for cation- and anioninsertion electrochemistry that opens possible new electro-synthetic routes.

\section{Conclusions}

The solid-state electrochemistry of malachite green (MG) in contact with $\mathrm{NaCl}$ aqueous electrolytes was used to test the possible potential-driven promotion of different solidto-solid transformations in ion-insertion solids, including the performance of successive cation and anion insertion processes. This electrochemistry clearly differs from the electrochemistry of the dye in the solution phase. The occurrence of oxidation with anion insertion, reduction with cation insertion and reduction with anion issue and the formation of segregated phases were also monitored using coupled AFM-VIMP and FIB-FESEM-VIMP experiments and were confirmed by HRFESM-EDX-VIMP experiments at the nanoscopic scale. Voltammetric and open circuit potential data are consistent with a theoretical thermochemical model describing such electrochemical processes in terms of separate contributions of ion and electron transport. 
Acknowledgements: Financial support from the Project CTQ2017-85317-C2-1-P (Ministerio de Economía, Industria y Competitividad (MINECO), Fondo Europeo de Desarrollo Regional (ERDF) and Agencia Estatal de Investigación (AEI)), is gratefully acknowledged. 


\section{References}

1 F. Marken and A. Atobe, Eds. Modern Electrosynthetic Methods in Organic Chemistry, CRC Press -Taylor and Francis, Boca Raton, 2018.

2 D. Gningue-Sall, M. Fall, M. M. Dieng, J. J. Aaron and P. C. Lacaze, Phys. Chem. Chem. Phys., 1999, 1, 1731-1734.

3 M. T. Giacominia and R. Schuster, Localized electrosynthesis of polypyrrole by application of short voltage pulses. Phys. Chem. Chem. Phys., 2005, 7, 518-523.

4 M. F. Suárez-Herrera, M. Costa-Figueiredo and J. M. Feliu, Phys. Chem. Chem. Phys., 2012, 14, 14391-14399.

5 S. Komorsky-Lovric, J. Solid State Electrochem., 1997, 1, 94-99.

6 A. Schauf $\beta$ and G. Wittstock, J. Solid State Electrochem., 1999, 3, 361-369.

7 M. Giorgetti, L. Guadagnini, D. Tonelli, M. Minicucci and G. Aquilanti, Phys. Chem. Chem. Phys., 2012, 14, 5527-5537.

8 F. Scholz, L. Nitschke and G. Henrion, Naturwiss., 1989, 76, 71-72.

9 F. Scholz, L. Nitschke, G. Henrion and F. Damaschun, Naturwiss., 1989, 76, 167-168.

10 F. Scholz, L. Nitschke and G. Henrion, Fresenius' Z. Anal. Chem., 1989, 334, 56-58.

11 F. Scholz and B. Meyer, Chem. Soc. Rev., 1994, 23, 341-347.

12 F. Scholz and B. Meyer, Voltammetry of solid microparticles immobilized on electrode surfaces, in Electroanalytical Chemistry, A Series of Advances, A.J Bard and I. Rubinstein, Eds., 20, pp. 1-86. Marcel Dekker, New York.

13 T. Grygar, F. Marken, U. Schröder and F. Scholz, Coll. Czech. Chem. Commun., 2002, 67, 163-208.

14 F. Scholz, U. Schröder, R. Gulaboski and A. Doménech-Carbó, Electrochemistry of Immobilized Particles and Droplets, $2^{\text {nd }}$ edit. Springer, Berlin-Heidelberg, 2014.

15 A. Doménech-Carbó, J. Labuda and F. Scholz, Pure Appl. Chem., 2013, 85, 609-631.

16 G. Inzelt, J. Solid State Electrochem., 2002, 6, 265-271.

17 A. M. Bond, S. Fletcher, F. Marken, S. J. Shaw and P. J. Symons, J. Chem. Soc. Faraday Trans., 1996, 92, 3925-3933.

18 A. Vuorema, P. John, A. Toby, A. Jenkins and F. Marken, J. Solid State Electrochem., 2006, 10, 865-871. 
19 Y. Jin, K. J. Edler, F. Marken and J. L. Scout, Green Chem., 2014, 16, 3322-3327.

20 A. Kolodziej, S. D. Ahn, M. Carta, R. Malpass-Evans, N. B.. McKeown, R. S. L. Chapman, S. D. Bull and F. Marken, Electrochim. Acta, 2015, 160, 195-201.

21 D. Kaluza, M. Jöhnsson-Niedziólka, S. D. Ahn, R. E. Owen, M. D. Jones and F. Marken, J. Solid State Electrochem., 2015, 19, 1277-1283.

22 F. Marken, J.D. Watkins and A.M. Collins, Phys. Chem. Chem. Phys., 2011, 13, 10036-10047.

23 A. Dostal, B. Meyer, F. Scholz, U. Schroder, A. M. Bond, F. Marken and S. J. Shaw, J. Phys. Chem., 1995, 99, 2096-2103.

24 F. Scholz and A. Dostal, Angew. Chem. Int. Ed. 1995, 34, 2685-2687.

25 H. Kahlert, U. Retter, H. Lohse, K. Siegler and F. Scholz, J. Phys. Chem. B, 1998, 102, 8757-8765.

26 A. Doménech-Carbó and M. T. Doménech-Carbó, J. Solid State Electrochem., 2006, 10, 949-958.

27 A. Doménech-Carbó, P. Navarro, V. J. Arán, B. Muro, N. Montoya and E. GarcíaEspaña, Analyst, 2010, 135, 1449-1455.

28 R. Cisternas, H. Kahlert, H. Wulff and F. Scholz, Electrochem. Commun. 2015, 56, 34-37.

29 H. Bach, F. G. K. Baucke and D. Krause, Eds. Electrochemistry of glasses and glass melts, including glass electrodes, Springer, Berlin, 2001.

30 F. G. K. Baucke, J. Solid State Electrochem. 2011, 15, 23-46.

31 A. Doménech-Carbó, I. O. Koshevoy and N. Montoya, J. Solid State Electrochem. 2016, 20, 673-681.

32 M. D. Pandey, V. Martí, M. I. Burguete, N. Montoya, S. V. Luis, E. García-España and A. Doménech-Carbó, RSC Adv. 2016, 6, 35257-35266.

33. R. A. W. Dryfe, Phys. Chem. Chem. Phys., 2006, 8, 1869-1883.

34 P. Sun, F. O. Laforge and M. V. Mirkin, Phys. Chem. Chem. Phys., 2007, 9, 802-823.

35 S. M. MacDonald, M. Opallo, A. Klamt, F. Eckert and F. Marken, Phys. Chem. Chem. Phys., 2008, 10, 3925-3933.

36 M. Hermes, M. Lovric, M. Hartl, U. Retter and F. Scholz, J. Electroanal. Chem., 2001, 501, 193-204. 
37 P. G. Pickup, C. R. Leidner, P. Denisevich, K. W. Willman and R. W. Murray, J. Electroanal. Chem., 1984, 164, 39-61.

38 C. P. Leidner, P. Denisevich, K. W. Willman and R. W. Murray, J. Electroanal. Chem., 1984, 164, 63-78.

39 X. Qu, A. Nafady, A. Mechler, J. Zhang, A. R. Harris, A. P. O’Mullane, L. L. Martin and A. M. Bond, J. Solid State Electrochem. 2008, 12, 739-746.

40 A. Nafady, A. M. Bond, V. Qu and L. L. Martin, J. Solid State Electrochem., 2013, 17, 1609-1620.

41 H. Kitching, A.J. Kenyon and I.P. Parkin, Phys. Chem. Chem. Phys., 2014, 16, 6050-6059.

42 J. Karpiuk, Phys. Chem. Chem. Phys., 2003, 5, 1078-1090.

43 T. Funada, T. Hirose, N. Tamai and H. Yao, Phys. Chem. Chem. Phys., 2015, 17, 11006-11013.

44 A. Doménech-Carbó, M. T. Doménech-Carbó, M. Silva, F. M. Valle-Algarra, J. V. Gimeno-Adelantado, F. Bosch-Reig and R. Mateo-Castro, Analyst, 2015, 140, 1065-1075.

45 R. N. Renaud, C. J. Stephens and G. Brochu, Can. J. Chem., 1984, 62, 565-569.

46 S. Singh, V. Ch. Srivastava and I. D. Mall, J. Phys. Chem. C, 2013, 117, $15229-15240$.

47 D. Zhu, Q. Li, K. C. Honeychurch, M. Piano and G. Chen, Anal. Lett. 2015, 49, 1436-1451.

48 S. Singh, S. L. Lo, V. C. Srivastava and A. D. Hiwarkar, J. Envir. Chem. Eng., 2016, 4, 2911-2921.

49 M Lovric and F. Scholz, J. Solid State Electrochem., 1997, 1, 108-113.

50 K. B. Oldham, , J. Solid State Electrochem., 1998, 2, 367-377.

51 M. Lovric, M. Hermes and F. Scholz, , J. Solid State Electrochem., 1998, 2, 401-404.

52 M. Lovric and F. Scholz, , J. Solid State Electrochem., 1999, 3, 172-175.

53 U. Schröder, K. B. Oldham, J. C. Myland, P. J. Mahon and F. Scholz, J. Solid State Electrochem., 2000, 4, 314-324.

54 A. K. Neufeld, I. Madsen, A. M. Bond, and C. F. Hogan, Chem. Mater., 2003, 15, 3573-3585. 
55 A. R. Harris, A. Nafady, A. P. O’Mullane and A. M. Bond, Chem. Mater., 2007, 19, 5499-5509.

56 A. Nafady, A. M. Bond and A. P. O’Mullane, Inorg. Chem., 2009, 48, 9258-9270.

57 A. Doménech-Carbó, I. O. Koshevoy, N. Montoya and T. A. Pakkanen, Electrochem. Commun., 2010, 12, 206-209.

58 A. Doménech-Carbó, I. O. Koshevoy, N. Montoya and T. A. Pakkanen, Anal. Bioanal. Chem., 2010, 397, 2013-2022.

59 A. Doménech-Carbó, I. O. Koshevoy, N. Montoya and T. A. Pakkanen, Electrochem. Commun., 2011, 13, 96-98.

60 A. Nafady, N. J. Al-Qahtani, K. A. Al-Farhan, S. Bhargava and A. M. Bond, J. Solid State Electrochem., 2014, 18, 851-859.

61 A. Nafady, Y. M. Sabri, A. E. Kandjani, A. M. Alsalme1, A. M. Bond and S. Bhargava, J. Solid State Electrochem., 2016, 20, 3303-3314. 


\section{Figures}

Figure 1. CVs of: a) ca. $0.30 \mathrm{mM}$ solution of $\mathrm{MG}$ in $1.0 \mathrm{M} \mathrm{NaCl}$ aqueous solution and b) a microparticulate deposit of the dye on a graphite bar in contact with $1.0 \mathrm{M} \mathrm{NaCl}$. Potential scan initiated at $-0.20 \mathrm{~V}$ vs. $\mathrm{Ag} / \mathrm{AgCl}$ in the positive direction; potential scan rate $50 \mathrm{mV} \mathrm{s}^{-1}$.

Figure 2. $2^{\text {nd }}$ and subsequent potential scans recorded in CVs of: a) ca. $0.30 \mathrm{mM}$ solution of $\mathrm{MG}$ in $1.0 \mathrm{M} \mathrm{NaCl}$ aqueous solution and b) a microparticulate deposit of the dye on a graphite bar in contact with $0.10 \mathrm{M} \mathrm{NaCl}$. Potential scan initiated at $-0.20 \mathrm{~V}$ vs. $\mathrm{Ag} / \mathrm{AgCl}$ in the positive direction; potential scan rate $50 \mathrm{mV} \mathrm{s}^{-1}$. Semi-derivative convolution of data was applied to increase peak resolution.

Figure 3. Electrochemical pathway proposed to describe the solution-phase voltammetry of $\mathrm{MG}$ in $\mathrm{NaCl}$ media.

Figure 4. Topographic AFM images of an MG grain on a graphite plate in contact with $0.10 \mathrm{M} \mathrm{NaCl}$ aqueous solution a) before and b-d) after application of successive potential inputs of b) 0.50, c) -0.25 , d) $0.25 \mathrm{~V}$ vs. $\mathrm{Ag} / \mathrm{AgCl}$ for $5 \mathrm{~min}$ each.

Figure 5. a,b) EDX spectra and c,d) FESEM images of MG grains. a,c) after application of an oxidative step at $0.80 \mathrm{~V}$ and (b,d) after the subsequent application of a reductive step at $-0.25 \mathrm{~V}$.

Figure 6. FESEM images of; a) a MG crystal after application of a $0.50 \mathrm{~V}$ potential for 5 min in contact with $0.10 \mathrm{M} \mathrm{NaCl}$ and b-d) the trenches performed by FIB on b) the above crystal, c) an MG crystal submitted successively to 5 min potential steps at 0.50 and $-0.25 \mathrm{~V}, \mathrm{~d})$ an MG crystal submitted successively to 5 min potential steps at 0.50 , -0.25 and $0.25 \mathrm{~V}$.

Figure 7. Proposed electrochemical processes for the electrochemical oxidation of microparticulate MG deposits in contact with aqueous chloride-containing electrolytes.

Figure 8. Time variation of: a) $E_{\mathrm{OCP}}$, and b) $\Delta E_{\mathrm{OCP}} / \Delta t$ for microparticulate deposits of MG on a graphite electrode in contact with $1.0 \mathrm{M} \mathrm{NaCl}$ after application of a $1.0 \mathrm{~V}$ potential input for 5 min (black), and after application of successive constant potential steps for 5 min each at 0.35 (olive green) and $-0.25 \mathrm{~V}$ (green), and after application of 10 potential cycles between 0.35 and $-0.25 \mathrm{~V}$ at $50 \mathrm{mV} \mathrm{s}^{-1}$ (red).

Figure 9. Pictorial representation of the solid-state electrochemical processes for MG crystals in contact with aqueous $0.10 \mathrm{M} \mathrm{NaCl}$. a) Oxidative/reductive dissolution; b) cation or anion assisted solid-to-solid transformation. 
Figure 1
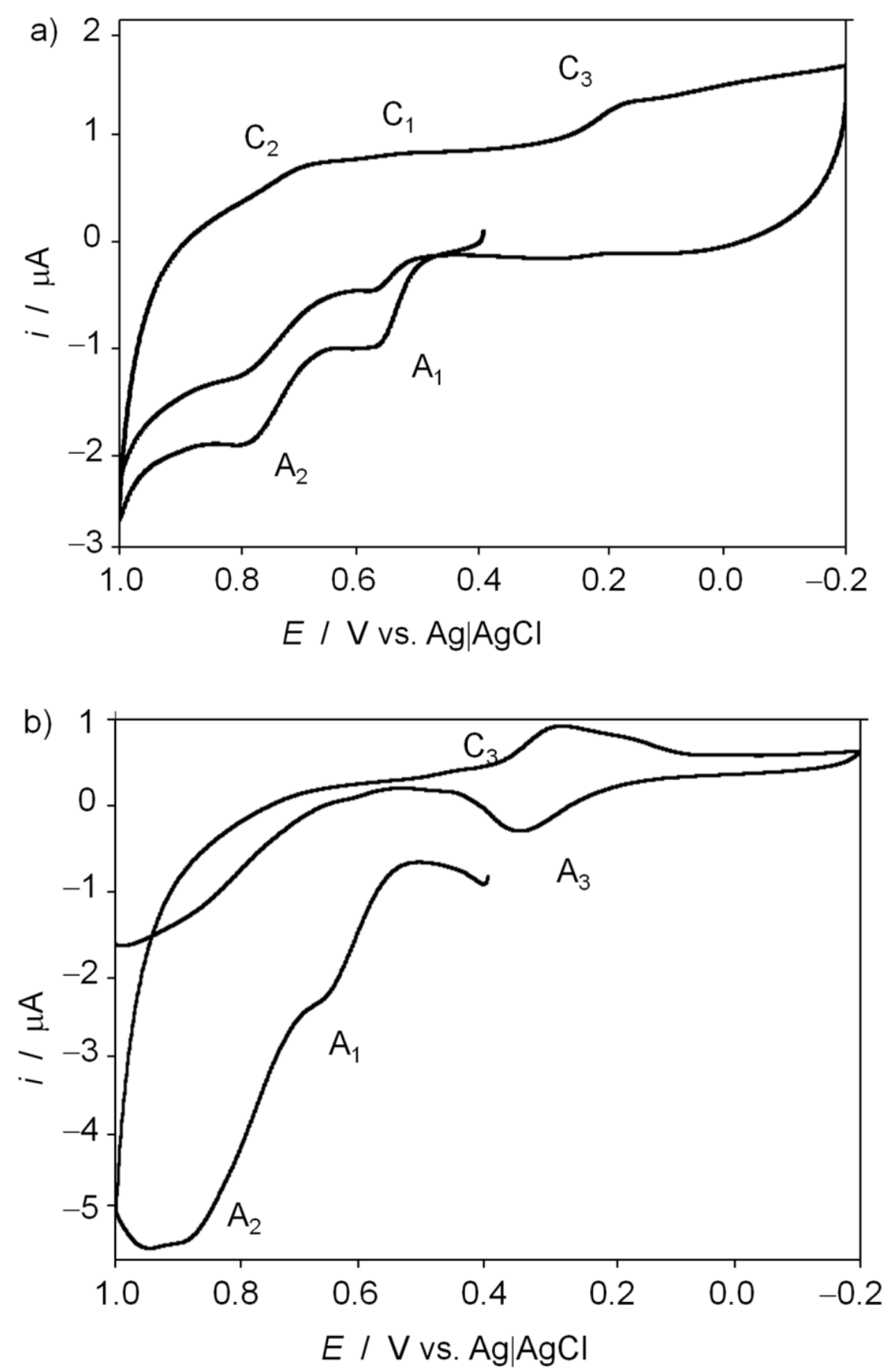
Figure 2

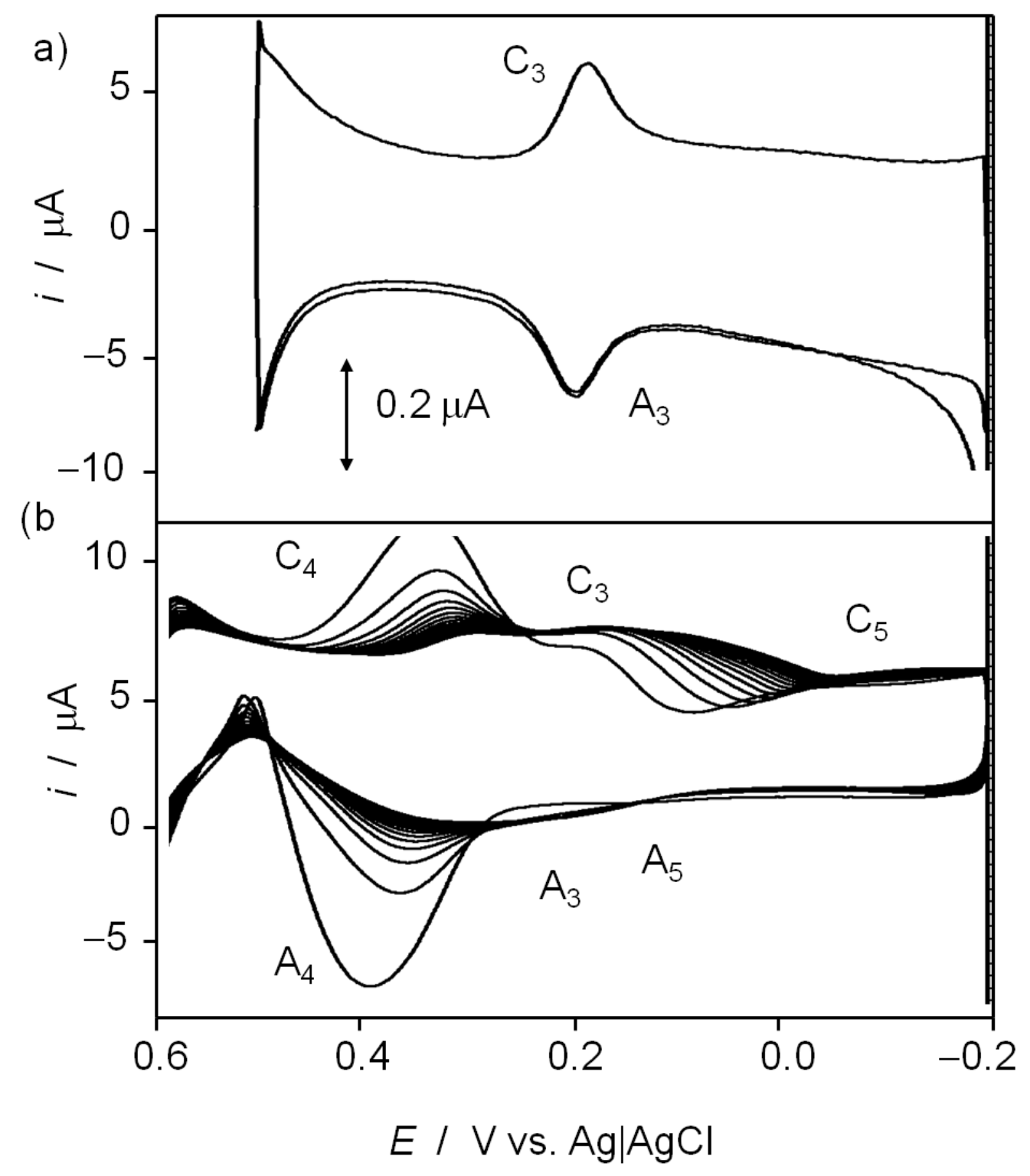


Figure 3<smiles>CN(C)c1ccc(C(=C2C=CC(=[N+](C)C)C=C2)c2ccccc2)cc1</smiles><smiles>CN(C)c1ccc(C(c2ccccc2)c2ccc(N(C)CO)cc2)cc1</smiles> 
Figure 4
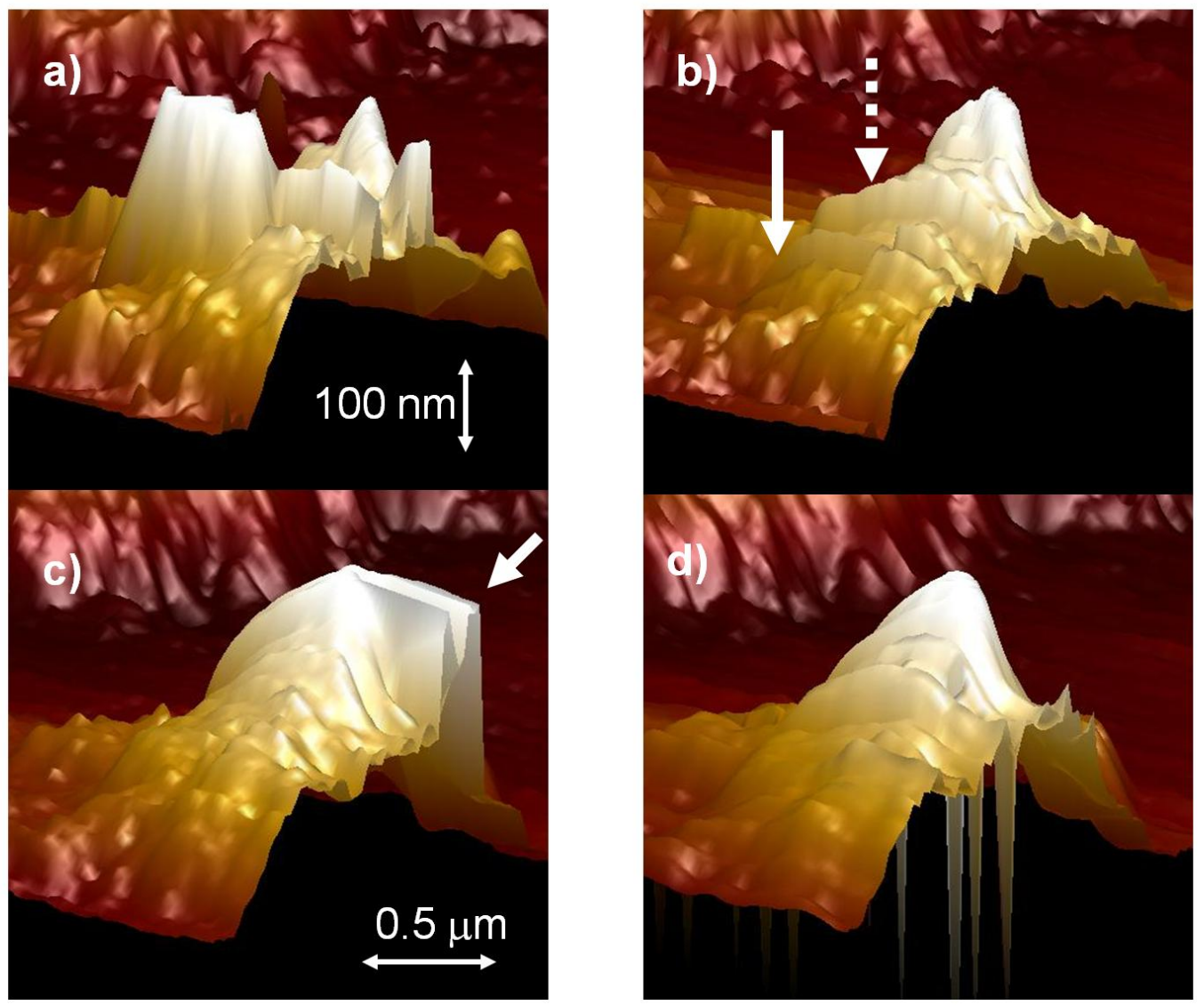
Figure 5
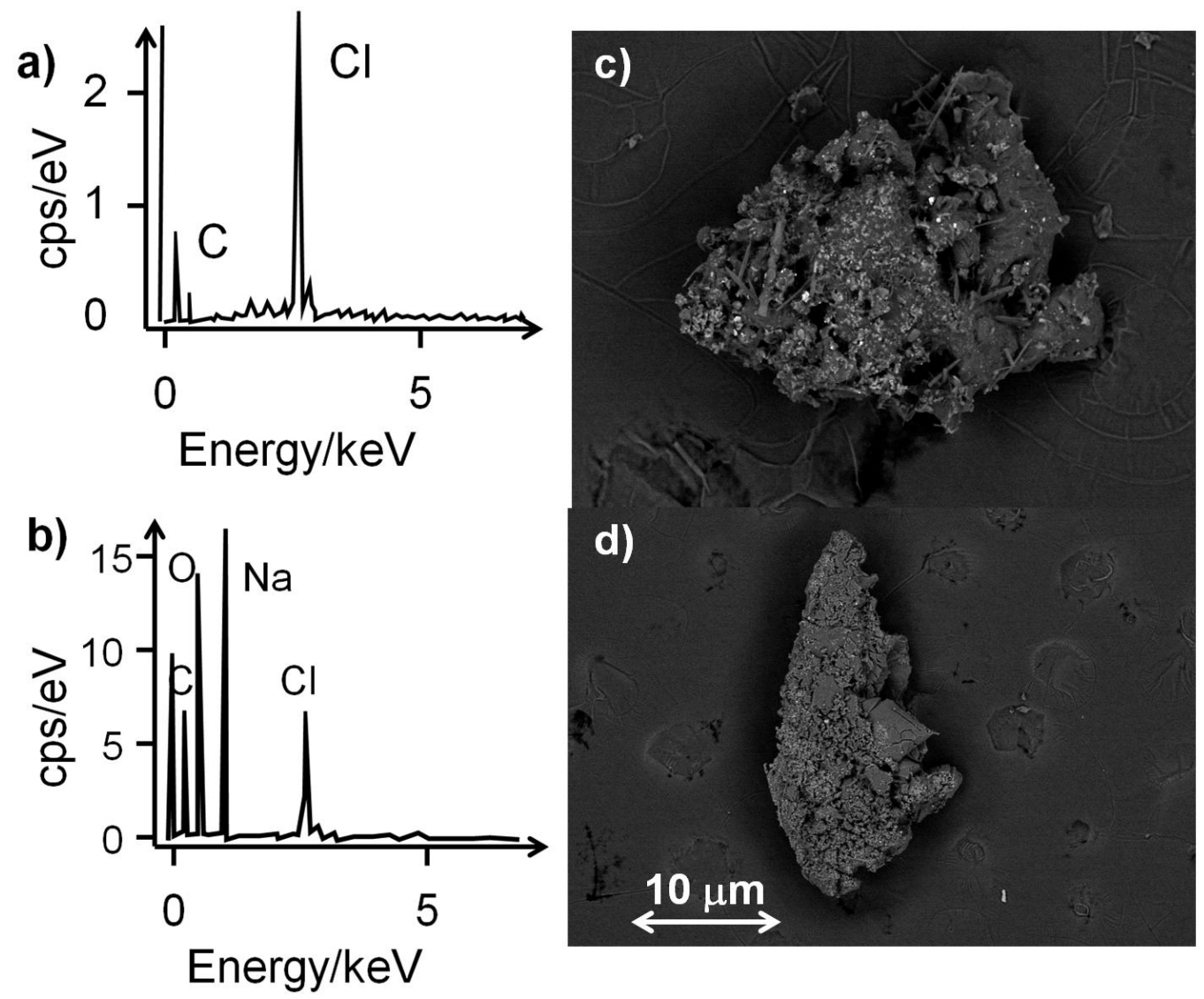
Figure 6
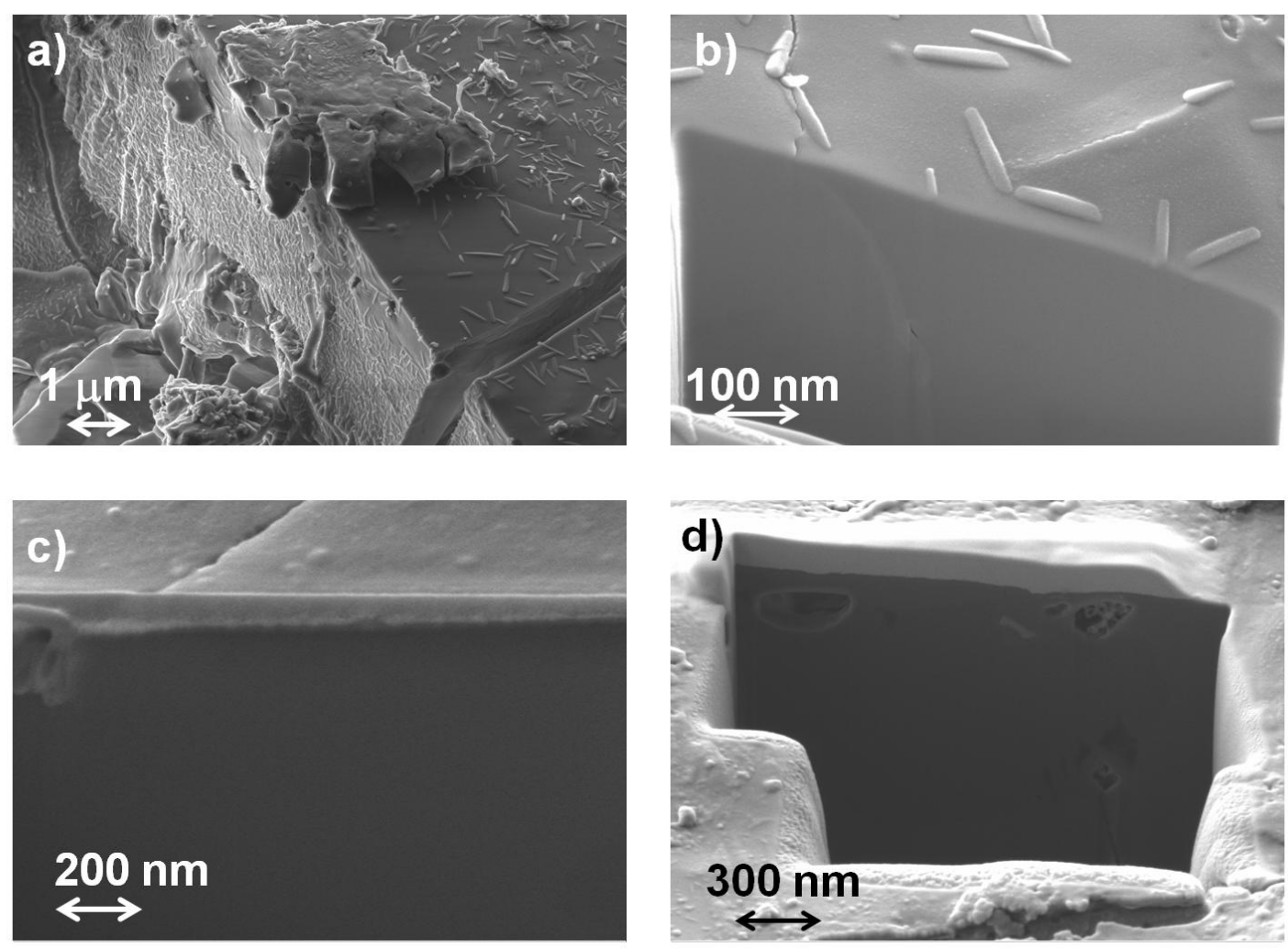
Figure 7<smiles></smiles>

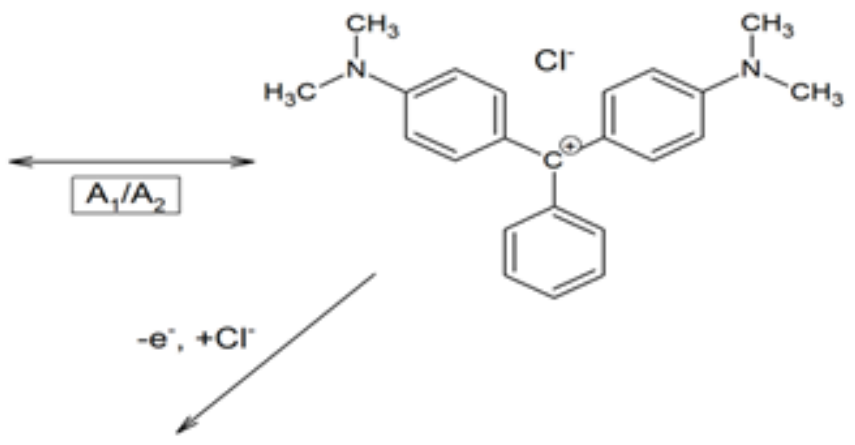<smiles>CN(C)c1ccc(C(c2ccccc2)(c2ccccc2)c2ccc([N+](C)(C)Cl)cc2)cc1</smiles>
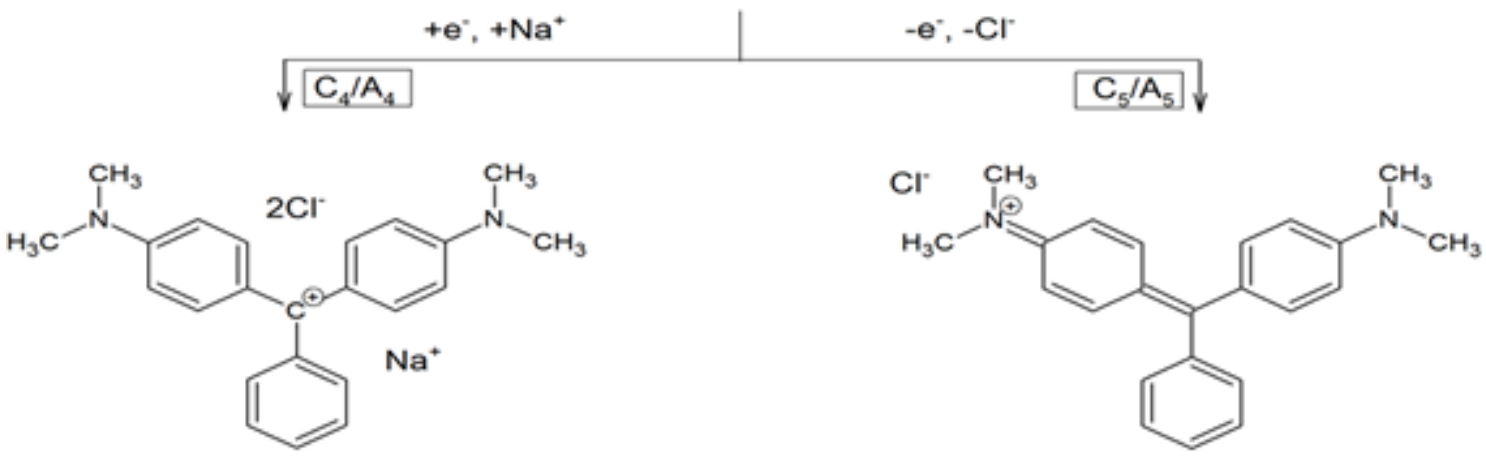

26 
Figure 8

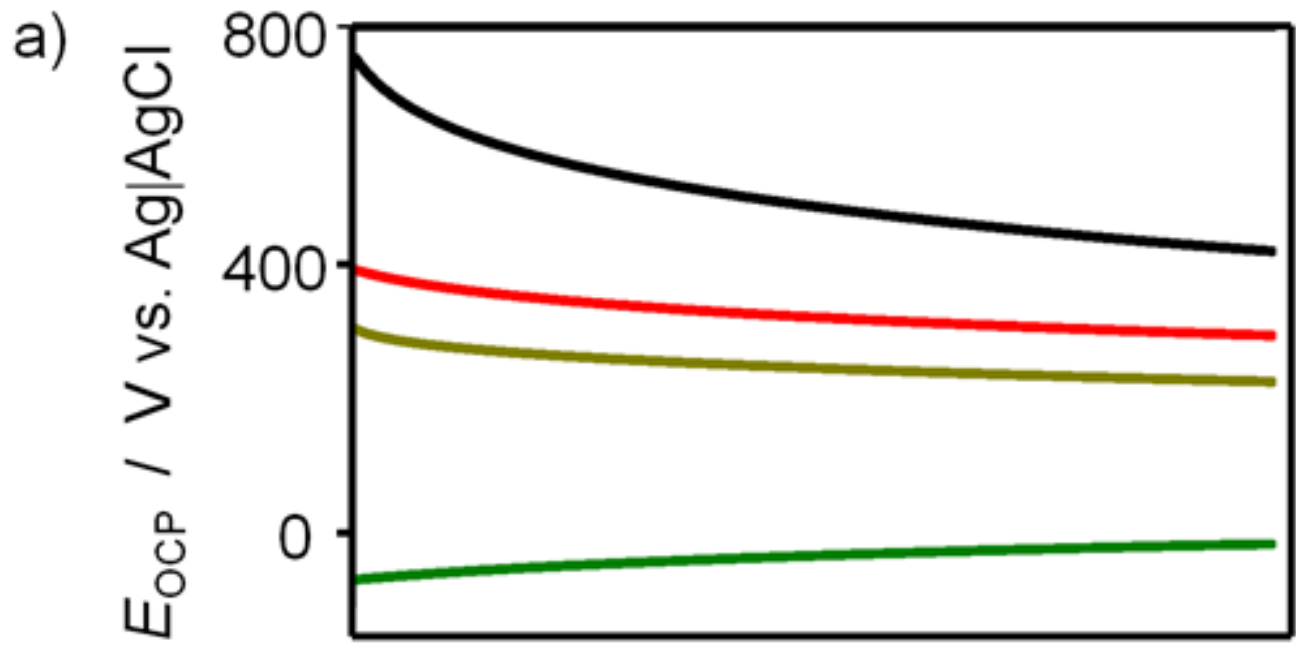

b) is

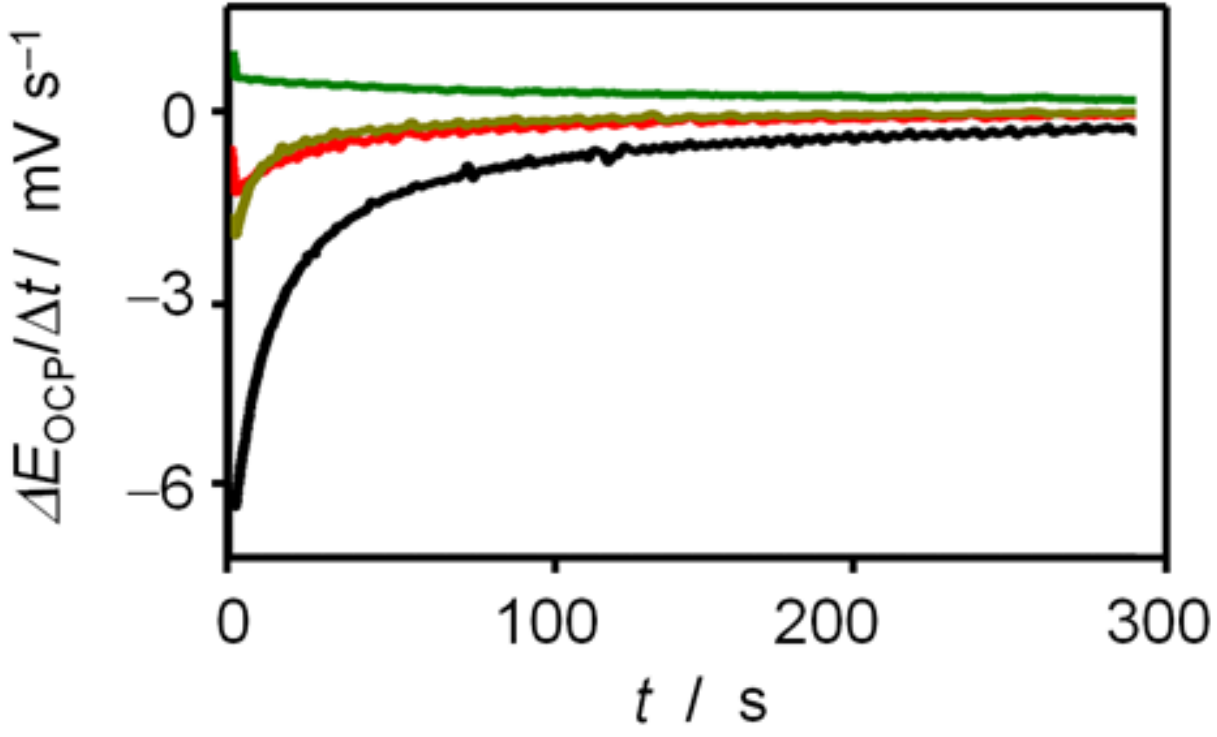


Figure 9

a)

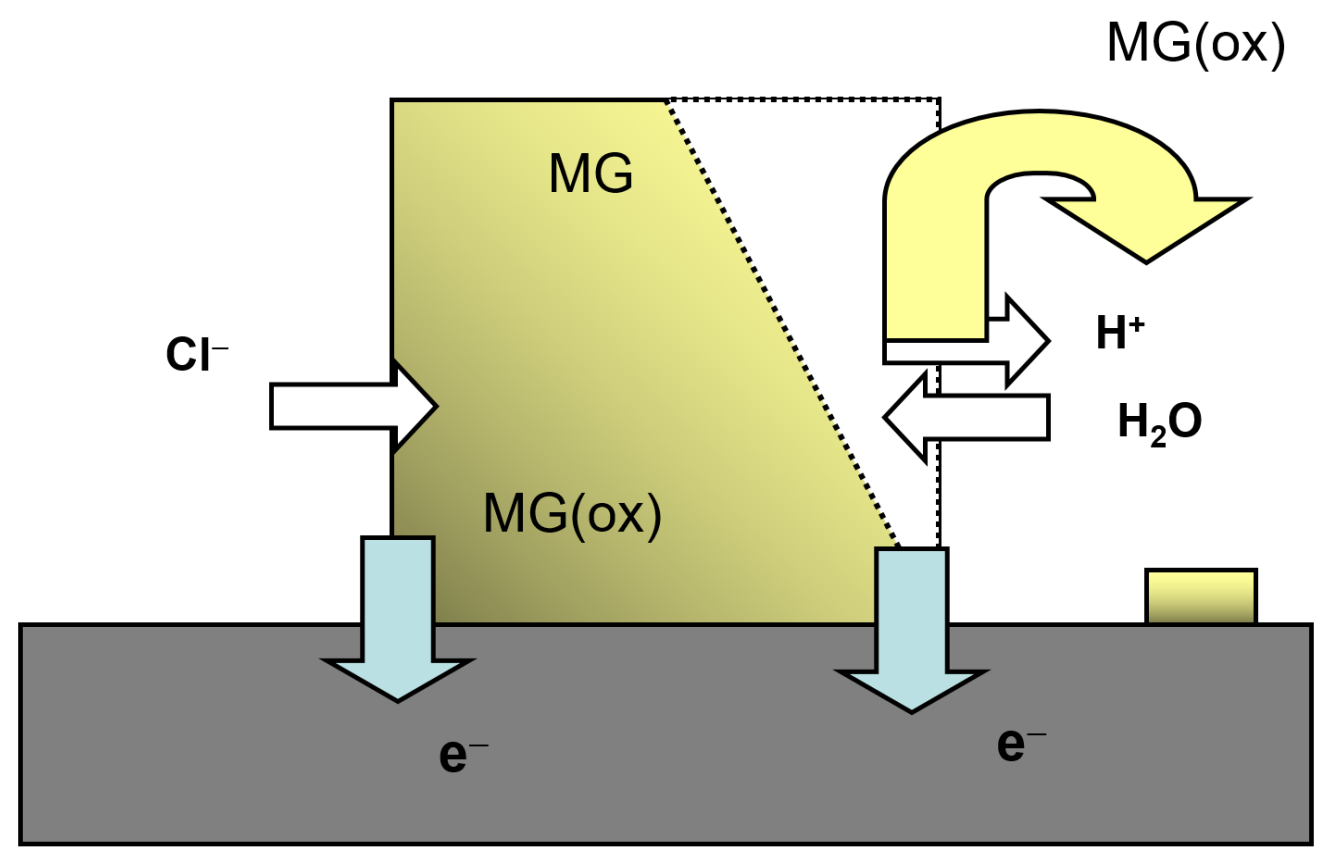

b)

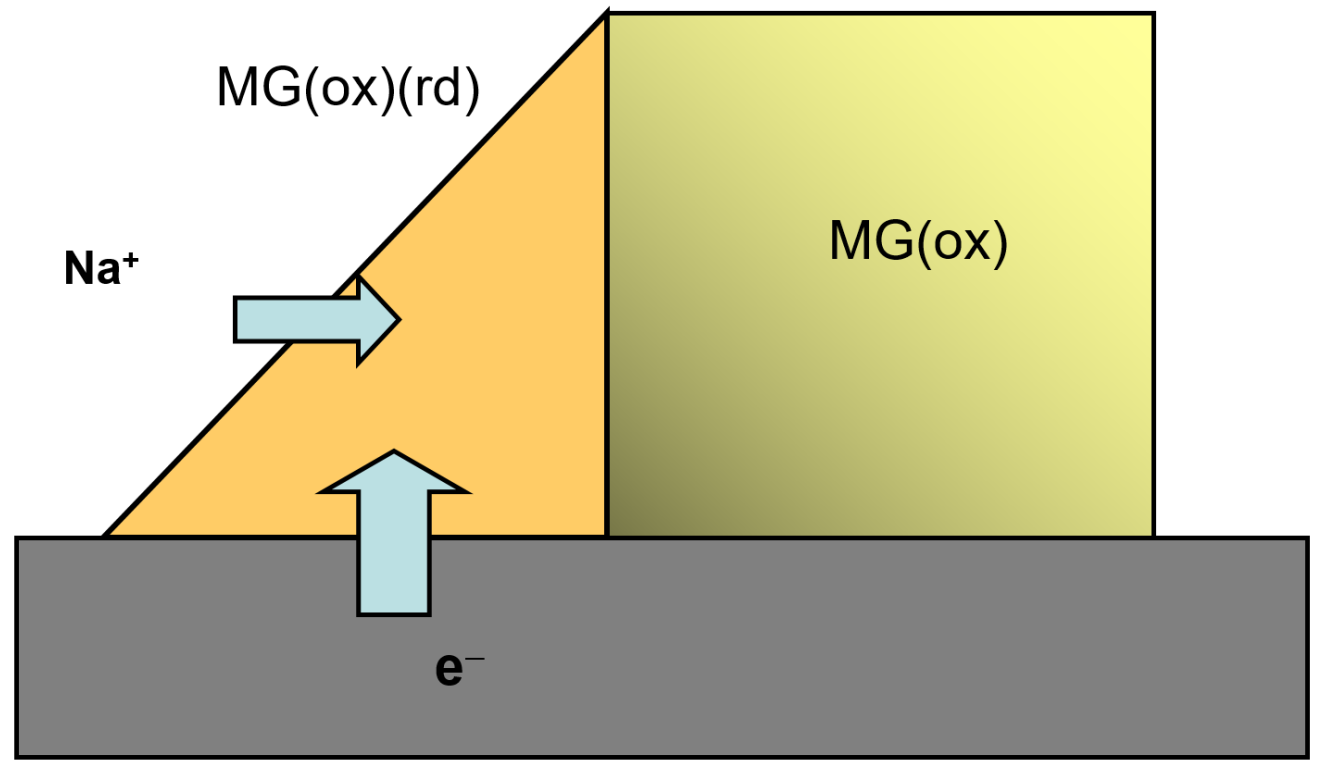

